\title{
The Appraisals Used by Indonesian and Filipino Teachers in Casual Conversation
}

\author{
Rachel Kartika Sari ${ }^{\bowtie}$, Januarius Mujianto, Helena I. R. Agustien
}

Universitas Negeri Semarang, Indonesia

\begin{tabular}{l} 
Article Info \\
\hline Article History: \\
Accepted 28 \\
November 2020 \\
Approved 06 January \\
2021 \\
Published 15 March \\
2021
\end{tabular}

Keywords: Appraisal, Casual Conversation, Culture, Teachers

\begin{abstract}
The Appraisal system is a comprehensive framework that prominently accommodates word classification. These words reflect the feelings and attitudes of the speakers that might implicitly be influenced by culture and norms. To find out the differences and similarities, transcribed conversations of Indonesian and Filipino teachers in Maria Regina School were analyzed. A qualitative method is applied to interpret the findings. The manifestation of attitude, judgment, and graduation are classified accordingly based on Martin and White (2005). The finding of this research is then supported and related to the values and culture that ground the way teachers express appraisal in conversation. The result indicates that teachers are dominant in the engagement system, especially entertain items. These items reflect kinship and open discussion among teachers through questions and the use of modals. In the attitude systems, Filipino teachers are more dominant in positive security that reflect confidence and togetherness while positive happiness items are found in Indonesian teachers where they express their fascination and contentment. Indonesian teachers tend to express judgment of normality while Judgement of capability was expressed more by Filipino teachers. In the graduation system, teachers mostly use force intensification to express the degree of intensity, repetition, and quality. The significance of the research is, the readers will learn to be more considerate in expressing their feeling and emotion in casual talk, especially with people who have different backgrounds of culture.
\end{abstract}

\footnotetext{
${ }^{凶}$ Correspondence Address :

p-ISSN 2087-0108

KampusPascasarjanaunnes, semarang. Jl. KeludUtara III Semarang e-ISSN 2502-4566

E-mail : rachelivygreen@gmail.com
} 


\section{INTRODUCTION}

Teachers have ways to connect in a conversation despite works that they must tackle and accomplish professionally. According to Jian and Dalisay (2014), a conversation might create productive working relationships, increasing motivation, and minimize the perception of power and control. The familiarity and kinship are built through casual conversation with possible topics that come up as the conversation goes on. There are chances that teachers pour their feelings and express their emotions since the nature of casual conversation is intimate and diverting through small talks and spontaneous turn-taking. Therefore, an appraisal framework is adopted to analyze the attitude and feelings of Indonesian and Filipino teachers. Appraisal systems are chosen for their comprehensive and complex classification that accommodates the manifestation of words to be plotted based on the categories provided, such as attitude, engagement, and graduation (Martin and White, 2015). Attitude focus on feeling, perception, and discernment towards human or even things. In Engagement, speakers positioned themselves as the claim maker and opinion initiators that find their way to orient themselves by considering the position of other speakers. The degree and intensifier of feeling are classified in graduation category. Several researchers was conducted to analyze the appraisal resources in various fields of the study such as analyzing campaign speeches. (Novi et al.,2019), similarities and differences of appraisal in eulogies that conveyed relationships toward John McCain (Pratiwi et.al, 2020), Negative rhetoric posted on social media (Cadwell \& Rose, 2020) classroom talks (Cha \& Messa, 2010), attitude found in the news article (Lestari, 20008), and comparison of appraisal Resources used in a persuasive essay with different level of proficiency (Fauziah et al.,2019).

An appraisal framework is implemented to emphasize the focal point of this research, which is to interpret the similarities and differences of how Indonesian and Filipino teachers use those categories in their talks. Feeling, such as in/security, $\mathrm{u} / \mathrm{hap}$, etc and attitude expressed by each speaker might be caused by some factors, including barriers, cultural gaps (Domingo, 2017), and work-related cultural differences. Each culture certainly has a characteristic that forms the social pattern and character of an individual. For example, the concept of kinship is implemented by Indonesian (Hermawan \& Looo, 2019), bayanihan, or the fostering of camaraderie and sense of involvement and engagement by Filipinos with strangers (Selmer \& Leon, 2003), and attributes as manang (older sister), kuya (older brother), tita (aunt) as an act of Filipinos to foster familiarization of others (Morrillo, 2020). This social pattern is reflected through the interaction. For Indonesian, togetherness is reflected through sympathy and empathy. A decrement will come up when people tend to avoid or abandoned the practice of certain values. Discernment or judgment carry out the meaning of being ethical or proper in the hierarchy of social structure (Riany et.al.,2016). For example, the rule of a woman in the society (Andajani et al 2016) and norms of hierarchy in the family (Medina, 2001), and reciprocity of responsibility to take care of the elders (Selmer \& Leon, 2003). Conducting certain behavior while interacting is also leading themselves to judgment. For example, hiya or malu refers to how uncomfortable or shameful if they do something wrong, incorrectly meet their authority's expectation (Caparas \& Hartijasti, 2017).

Based on the previous researches, the occurred similarities and differences found in the conversation of teachers are worth-investigating. The participants of the research are the teachers of Maria Regina School Semarang. Maria Regina is the pioneer of a modern Catholic school in Semarang that implements national and international curricula to provide dual certifications to its students. The students experience chances to learn from both professional and dedicated Indonesian and Filipino teachers who work in unity in diversity of culture. The exposure of the diverse culture in Maria Regina School has made the researcher is determined to take Indonesian and Filipino teachers as the participant of the research. The 
purpose of this research is aimed to achieve the understanding of maintaining the confidence of the students and teachers in building a positive and convenient atmosphere in conversation with people that have different backgrounds of cultures.

\section{METHODS}

The presented study belongs to qualitative research that refers to the interpretation of analyzed data to provide a comprehensive and complex description of particular cases and perform comparisons across research settings. The important features on the aspects of this research are spontaneity, interactivity, interpersonality and coherence (Thornbury, 2005) They are 8 teachers as the participants of this research. The conversation was recorded and transcribed. The words are then classified accordingly based on the appraisal system that consists of Attitude, Engagement, and Graduation. The previous research's findings are going to be related to the data obtained to strengthen the finding of this study. The data collection procedure of the study has adopted quantitative, for the statistic of the number of utterances classified, and qualitative methods to conduct a comparative analysis of the use of appraisal found in the transcribed conversation. The names of the participants are represented by the initial " $F$ " is for Filipino teachers while " $\mathrm{I}$ " is for Indonesian.

\section{RESULTS AND DISCUSSION}

The result of the classified words of 8 teachers is counted and summed. The following tables in the summary of appraisal used by Indonesian teachers.
Table 1. The Reoccurrence of Appraisal by Indonesian Teacher.

\begin{tabular}{lll}
\hline $\begin{array}{l}\text { Appraisal } \\
\text { Category }\end{array}$ & $\begin{array}{l}\text { Indonesian } \\
\text { Teachers }\end{array}$ & $\begin{array}{l}\text { Percenta } \\
\text { ge }\end{array}$ \\
\hline Attitude & 504 & 26 \\
Engagement & 1196 & 62 \\
Graduation & 240 & 12 \\
\hline Total & 1940 & 100 \\
\hline
\end{tabular}

Table 2. The Recurrences of Attitude Distribution.

\begin{tabular}{llll}
\hline Attitude & & Recurrences & $(\%)$ \\
\hline Affect & + & 66 & 13 \\
& - & 72 & 14 \\
Judgment & + & 88 & 18 \\
& - & 95 & 19 \\
Appreciation & + & 139 & 28 \\
& - & 36 & 7 \\
\hline Total & & 460 & 100
\end{tabular}

Table 3. The Recurrences of Engagement Distribution.

\begin{tabular}{lllll}
\hline Engagement & & & Recurrences & $(\%)$ \\
\hline Monoglos & & & 53 & 4 \\
& & & & \\
\hline & Disc. & deny & 158 & 13 \\
& & count. & 234 & 20 \\
\cline { 2 - 5 } Heterogloss & Proc. & con. & 127 & 11 \\
& & pro. & 91 & 8 \\
& & end. & 31 & 3 \\
\cline { 2 - 5 } & Entertain & 452 & 38 \\
\cline { 2 - 5 } & Att. & ack. & 46 & 4 \\
\hline Total & & dist. & 4 & 4 \\
\hline
\end{tabular}


Table 4. The Recurrences of Graduation Distribution.

\begin{tabular}{llll}
\hline \multicolumn{2}{l}{ Graduation } & Recurrences & Percentage \\
\hline Force & quant. & 67 & 28 \\
& int. & 121 & 50 \\
\hline Focus & sharp & 2 & 1 \\
& soft & 50 & 21 \\
\hline Total & & 240 & 100 \\
\hline
\end{tabular}

Based on the reoccurrence of the appraisal items, there are 460 items found in the attitude category. The domination of the items is mostly found in the appreciation, especially the positive one. Positive items of satisfaction are frequently found in Indonesian teachers which indicate fascination of things that may lead to appreciation enunciated through the heeding of the details or particular precision of things (color, taste, ingredients, etc) discussed. The positive reaction is through the surge of happiness feeling and affections towards something. In the items of judgment capability and normality, Indonesian teachers concern more on the work accomplishment and well-being of others such as family, status, and role of woman in the family (Andajani-Sutjahjo et al., 2015)

The engagement items reached 1196 items. This category is the most prepotent among all categories. Entertain and disclaim are two significant reoccurrences found. The use of modals (would, could, etc) creates a subjectivity of the speakers when expressing their opinion via certain mental verb/ attribute projection that opens room for discussion for the hearer to give a further response that respects his/her statement. Rhetorical questions are mostly expressed by Indonesian teachers. Based on Martin and White (2015), the rhetorical question becomes the feature of entertain. A question is a form of rhetorical question that creates jokes which pointed out impossibility or contrast. The next items are disclaims. Items of disclaim were expressed through negation and connectives showing a contrast (but, yet, although) to express themselves odds with others or even unhappiness and dissatisfaction about things.
In the graduation feature, the category of focus indicated higher distribution found compared to graduation focus. In the subsystem of graduation focus, intensification has prominent reoccurrence items number. The intensification designated by Indonesian showed the speakers are unable to compare things and revealing how strongly they feel about things and repetition in talk. The words "so" and "very" serve as an intensifier and the pre-modification of an adjective. The items belong to the intensifier specify the highest possible intensity, including the adverb of frequency (always) and quantification of mass and number.

The next table is the summary of appraisal items reoccurrence from Filipino teachers.

Table 5. The Reoccurrence of Appraisal by Filipino Teacher.

\begin{tabular}{lll}
\hline Appraisal & Reoccurrence & $(\%)$ \\
\hline Attitude & 485 & 28 \\
Engagement & 1046 & 60 \\
Graduation & 212 & 12 \\
\hline Total & 1743 & 100
\end{tabular}

Table 6. The Recurrences of Attitude Distribution.

\begin{tabular}{llll}
\hline Attitude & & Recurrences & (\%) \\
\hline Affect & + & 96 & 20 \\
& - & 77 & 16 \\
Judgement & + & 148 & 31 \\
& - & 50 & 10 \\
Appreciation & + & 78 & 16 \\
& - & 36 & 7 \\
\hline Total & 486 & 100 \\
\hline
\end{tabular}


Table 7. The Recurrences of Engagement Distribution.

\begin{tabular}{lllll}
\hline Engagement & & & Recurrences & $(\%)$ \\
\hline Monogloss & & & 136 & 13 \\
\hline & Disc. & deny & 126 & 12 \\
& & coun. & 179 & 17 \\
\cline { 2 - 5 } Heterogloss & \multirow{3}{*}{ Proc. } & con. & 118 & 11 \\
& & pro. & 59 & 6 \\
& & end. & 2 & 0.2 \\
\cline { 3 - 5 } & Entertain & 390 & 37 \\
\cline { 2 - 5 } & \multirow{3}{*}{ Att. } & ack. & 35 & 3 \\
& & dis. & 1 & 0.1 \\
\hline Total & & & 1046 & 100 \\
\hline
\end{tabular}

Table 8. The Recurrences of Engagement Distribution.

\begin{tabular}{llll}
\hline Graduation & & Recurrences & $(\%)$ \\
\hline \multirow{2}{*}{ Force } & quant. & 67 & 32 \\
& int. & 105 & 50 \\
\hline \multirow{2}{*}{ Focus } & Sharp & 0 & 0 \\
& Soft & 40 & 19 \\
\hline Total & & 210 & 100
\end{tabular}

In the attitude category, the manifestation of judgment items is quite significant while affect proceeded as the second-highest items occurred after judgment. The reoccurrence of positive judgment and affect is higher than the negative ones. $16 \%$ of positive appreciation contributes to the positive items found in the talk. Those items are the expression of contentment, security, and self-confidence that might be the result of togetherness among others. The researcher found that Filipino enunciated judgment of normality and tenacity. These types of discernment lead to the parameter of how good and ethical a person is. Most of the judgment expressed is intended for one's self. The negative judgment of tenacity was expressed to indicate sensibility and determination. The frequency of negative affect is considered as consequential items since they reflect the sense of insecurities of Filipino teachers to face homesickness, cultural gaps (Domingo, 2017) and bear the responsibility of reciprocity (Selmer and De Leon, 2003) to take care of the family in the homeland and maintaining high regard to the elders or parents.
In the engagement category, the highest subcategories are entertain and disclaim items. The items of disclaim might also express a sense of insecurity. The speaker used negation to express the concession of such belief or claim. In the engagement system, the percentage of proclaim is $17 \%$ or 179 items found in the Filipino teachers' dialogue. Proclaim endorse is not found throughout the dialogue. The frequency of the "if clause" was mostly found from the talk of Filipino teachers. This clause indicates the possibility and room for discussion concerning the speakers. The researcher considers conditional if clause belongs to entertain because it construes the meaning of subjectivity possibility, probability or certain that another condition will happen (Mesa \& Chang, 2010). The next subcategory is attribute distance found. The attributes as the form of external resources used in the talks by speakers to distance/herself from the source and introducing varied perspectives that might give a room for discussion or dialogic space with the others.

The overall accumulation of graduation items by Filipino teachers is 212 items. The greatest number of items among all the subcategories is intensification. It reached 50\% compared to the other subsystems in graduation. The items related to force and focus are found throughout the conversation. Intensification can be found through lexical repetition or it is also known as reiteration in the level of lexical cohesion. Under the category of graduation focus, the speaker has a possibility to upscale or downscale the specification of things described that it will reach a marginal member of a certain category or a class membership. According to Martin and White (2005) hedges falls under the category focus where the speaker expressed a more precise degree of accuracy.

The further data is the elaboration of similarities and differences of appraisal used by Filipino and Indonesian teachers. 
Table 9. The Accumulated Similarities and Differences between Teacher's AppraisalAttitude.

\begin{tabular}{|c|c|c|c|}
\hline Attitude & Appraisal & Indonesian & Filipino \\
\hline \multirow[t]{6}{*}{ Affect } & \multirow[t]{2}{*}{ un/hap } & +39 & 35 \\
\hline & & -26 & 26 \\
\hline & \multirow[t]{2}{*}{$\mathrm{in} / \mathrm{sec}$} & +21 & 60 \\
\hline & & - 43 & 47 \\
\hline & \multirow[t]{2}{*}{ Dis/sat } & +6 & 1 \\
\hline & & -2 & 3 \\
\hline \multicolumn{2}{|l|}{ Total Affect } & 137 & 172 \\
\hline \multirow[t]{10}{*}{ Judgement } & \multirow[t]{2}{*}{ norm. } & +33 & 62 \\
\hline & & $\begin{array}{ll}- & 19\end{array}$ & 20 \\
\hline & \multirow[t]{2}{*}{ cap } & +43 & 49 \\
\hline & & $-\quad 26$ & 21 \\
\hline & \multirow[t]{2}{*}{ Ten } & +1 & 0 \\
\hline & & $-\quad 0$ & 1 \\
\hline & \multirow[t]{2}{*}{ ver } & +1 & 0 \\
\hline & & -1 & - \\
\hline & \multirow[t]{2}{*}{ prop } & $+\quad 10$ & 35 \\
\hline & & -4 & 8 \\
\hline \multicolumn{2}{|c|}{ Total Judgement } & 138 & 196 \\
\hline \multirow[t]{6}{*}{ Appreciation } & react. & $+\quad 114$ & 68 \\
\hline & & -36 & 32 \\
\hline & comp. & $+\quad 12$ & 5 \\
\hline & & -0 & 0 \\
\hline & val. & $+\quad 12$ & 5 \\
\hline & & -7 & 4 \\
\hline \multirow{2}{*}{\multicolumn{2}{|c|}{$\begin{array}{l}\text { Total } \\
\text { Appreciation }\end{array}$}} & 181 & 114 \\
\hline & & & \\
\hline
\end{tabular}

Table 10. The Accumulated Similarities and Differences of Teacher's Appraisal-Engagement.

\begin{tabular}{|c|c|c|c|c|}
\hline Engagement & & & Indonesian & Filipino \\
\hline Monogloss & & & 53 & 136 \\
\hline \multirow{8}{*}{ Heterogloss } & \multirow[t]{2}{*}{ Disclaim } & deny & 158 & 126 \\
\hline & & count. & 234 & 179 \\
\hline & \multirow[t]{3}{*}{ Proclaim } & con. & 127 & 118 \\
\hline & & & 91 & 59 \\
\hline & & end. & 0 & 0 \\
\hline & \multicolumn{2}{|l|}{ Entertain } & 452 & 390 \\
\hline & \multirow[t]{2}{*}{ Attribute } & ack. & 46 & 35 \\
\hline & & dist. & 4 & 1 \\
\hline Total & & & 1196 & 104 \\
\hline
\end{tabular}

Table 11. The Accumulated Similarities and Differences of Teacher's Appraisal- Graduation

\begin{tabular}{llll}
\hline \multicolumn{2}{l}{ Graduation Subsystem } & Filipino & Indonesian \\
\hline Force & quant & 67 & 67 \\
\cline { 2 - 4 } & int. & 105 & 121 \\
\hline Focus & Sharp & 0 & 2 \\
\cline { 2 - 4 } & Soft & 40 & 50 \\
\hline Total & & 213 & 240 \\
\hline
\end{tabular}

Based on the accumulated appraisal items, the similarities are elaborated and interpreted. In the category of attitude, the least items generated by teachers are dis/satisfaction. There is a propensity of teachers in expressing un/happiness in this category. The similarity was the same for the negative happiness. The total items are 26. The unhappiness expressed here indicated the moment that they used to have with family and friends that as for this moment, they work abroad or far from their family.

- F4: Like my mom would go to my brother's house or my sister's house for Christmas or the new year and since I've been away as well so the family has never met like...completed ...

\section{[Recording 3, turn 31]}

- I3 : I missed Jogja...[Recording 21, turn 73]

The next similarity is the appreciation items. Indonesian and Filipino teachers expressed higher positive appreciation than negative ones. Teachers use words related to positive reactions to evaluate things. For example:

- F1: $\quad$ Yes, It is a nice place ......most especially the sunrise [Recording 1, turn 34]

- I1: Ow the decoration's nice, miss.

\section{[Recording 2, turn 51]}

In the attitude category, Filipino teachers focus on the items of in/security. The classified items related to togetherness and assurance of Filipino teachers towards others. Filipino has a more dominant item in positive security that reached 60 items. It indicates togetherness 
confidence, and self -assurance (Martin \& White, 2005). In the culture of Filipino, togetherness is shown by offering someone to join the luncheon or gathering which is also expressed by Indonesian teachers that expressed kinship and communion (Hermawan \& Loo, 2019). For example:

- F2: Let's eat... [Recording 17, turn 17]

- I1: Hmm..yes..let's eat. Who wants to get it? [offering the food] [Recording 15, turn 37]

The sense of togetherness or involvement is in line with the finding of Selmer and Leon (2003). The sense of belonging in a group that shares the same references. Hofstede has pointed out that the Philippines' main defining feature as a society is collectivism, where the bond among members is maintained. Filipino involve others to join the gathering. The value of amor propio, or maintaining social attachment is highly regarded as a sense of togetherness.

The distribution of positive judgment of capability, tenacity, and propriety are enunciated by Indonesian and Filipino teachers. In the judgment of capability, teachers mostly use the modal "can" to mark out the skills, capacity, and capability. This example is taken from recording 3, turn 124, and 125.

- I1: But you oh.. you can drive a car.

- F4: Yes I can.

The lowest items found in the talk are the judgment of tenacity and veracity. There is only one statement that corresponds to this type of judgment. It evaluates the courage and dependability of someone through the judgment of tenacity. This judgment can be expressed through negation which means a positive characteristic of someone. For example:

- I3: you are not afraid to get to know other strangers there

Negative composition doesn't apply in the conversation. Positive items of composition and valuation reached the same number of occurrences. Teachers mostly expressed the simplicity and value of something. Here are examples of composition.
- F1: The ordinary vinegar, the rice one

\section{[Recording 7, turn 23]}

- I3: The ordinary vinegar, the rice one [Recording 9, turn 129]

The items of valuation expressed by mostly Indonesian teachers reflect the satisfaction of the speakers towards stuff with affordable with the expected quality or value.

- I3: Ow. It's cheap but it's good.

\section{[Recording 10, 62]}

The next category is engagement. The monologic items of Filipino are higher compared to Indonesian. It is believed that the assurance and confidence of a claim are maintained by Filipino teachers. This item reached 136 items found throughout the conversation. The similarities in the category of engagement are Indonesian and Filipino teachers showed a significant number of disclaim and entertain items. The similarity of the teacher in using engagement is, both speakers are dominant in using entertain among the rest of the categories. In casual conversation, both teachers are engaged and involved in a discussion that might require responses and subjective opinion. For Filipino, being involved, and maintaining a good relationship through talk is the form of interpersonal harmony (Porio \& Hollnsteiner, 1978). Maintaining harmony and showing engagement in talks is also reflected in the dominant number of entertainment items. The items of entertainment from Indonesia teachers occupied the highest number as well. Indonesian and Filipino teachers express entertainment by using modals, adverbs, questions, or the use of the phrase "I think" to open the room of discussion to prolong the conversation among colleagues. For example:

- I3: Maybe, because we smell the food, $I$ think. [Recording 10, turn 94]

- F4: I think..it is..Ah..no, chicken or meat? I forgot..[Recording 14, turn 29]

Most of the entertainment items of Indonesian teachers are expressed through questions to sustain the conversation. The 
questions mostly ask is about family as the form of friendliness and politeness to express an ambiance of closeness with their colleague. According to Efferin and Hartono (2015), the expression of the ambiance of closeness forms harmony and comfort. In the conversation, questions about family and status are frequently asked compared to Filipino teachers. For example:

- I4: What about your siblings, sir?

- F4: We are six in the family and I am the youngest. [Recording 22, turn 33 and 34]

The response to such questions is based on the fact that belongs to monogloss. The monogloss items related to such a claim that is believed to be the fact or the truth based on the speaker's point of view (Martin and White 2005). There are 136 monogloss items found in the talk that indicate lesser dialogic alternatives opened once Filipino teachers made a claim of bare assertion or mention a fact. The other difference found is, the Filipino teachers use "will" more frequent. There are 112 modals "will" be compared to Indonesia teachers that only reach 86 of modal "will". According to Fairclough, 2003) the use of modal will by Filipino teachers indicates a certain claim of future that justifies or convincing a certain course of action at this moment or the present.

The most frequent entertainment items used by Indonesian teachers are in the form of questions. Based on Martin and White, a rhetorical question can be included as entertain. The question is a form of rhetorical question in the form of jokes that pointed out impossibility or contrast For example:

- I2: And also for, the invitation card. We spend a lot of money

- I1: So what do you think? Do you want to write it one by one? [laughing] [Recording 2 , turn 134]

In the items of disclaim, teachers use negation and concession to show contrast. For example:
- I1: But I like the room, the hotel. It is not a five-star hotel but it has like ...instagramable place $==$ [Recording $\mathbf{1}$, turn 6]

- F2: Before, but now they just have 3 to 4 kids.

In disclaim proclaim, the least item of the speakers is endorse items. This item does not apply in the conversation while disclaim concur and pronounce dominate this subsystem. Disclaim is related to the warrantable proposition or agreement of both speakers. Both speakers might use the words "of course", "yes", "obviously" to express that they content with the truth and opinion of others. The result of disclaim proclaim can be related of how Indonesian and Filipino teachers appreciate and tend to avoid conflict. Filipinos are more on to set about interpersonal harmony by a blurring of the differences, and by agreement not to disagree - at least openly (Porio \& Hollnsteiner, 1978). In Indonesia, the notion of being tolerant and avoiding conflict in the process has become the value of societal interaction, including agreement. (Hermawan, 2019) . For example:

- FI: Just buy the cake and pizza?

- I3: Yeah..we can [Recording 7, turn 46]

In the attribute acknowledge has more items to be found. This item shows the distance of the speakers towards the claim that he/she make by relating to the external sources (Martin and White, 2015). The most frequent reoccurrence found is the word "said". For example:

- F4: And then the dance also, they said they can prepare also [Recording 12, turn 20]

- I3: My friend said that it is expensive...[Recording 1, turn 21]

The attribute of distance is the least items found throughout the talk. Filipino teachers only reached 1 item while there are 3 different items found in Indonesian teachers. Teachers are frequent in the acknowledge items. The message 
is attributed to someone other than the speaker through some plausible reasoning (Fraser, 2010). It might be assumed that both speakers stay clear of self-ascription by introducing the different speakers to make such a claim. The category of the distance of both teachers is the least. Indonesian teachers have higher items of this category while Filipino teachers have only one item throughout the conversation.

The last category is graduation. The similarity is in the item of quantities that reach the same amount of items distribution. Both speakers used approximators and adaptors (Prince, 1982) to indicate mass and number through the conveyed range. For example:

- F4: So, I have seen a lot of people [Recording 4, turn 8]

\section{- I1: So many [Recording 8, turn 31]}

The differences between both speakers are laid on the rest of the items. Intensification items used by Indonesian and Filipino teachers are weighty. The assigned number of items reached $50 \%$ compared to quantification units. However, the difference found through this item is on the intensification of repetition. Filipino has 21 or at least $9 \%$ repetition that emphasizes agreement, feeling, or disagreement while Indonesian more on to the intensification of quality that reached 101 items found among the rest of the items in force.

Under the category of focus, both speakers show the soft items more than the sharp. The distribution of sharp items is the least among all. Indonesian teachers applied the item of sharp that convey prototypicality. The word that is mostly used by Indonesian is "like" which has a similar meaning to "sort of" or "kind of" to construe the meaning of similarity. This word is applicable to be in soft items for teachers. The word like and sort of used may cause fuzziness/ vagueness. Through the vagueness, the speakers are trying to be as informative as possible or to convince the estimation or similarity of the other speakers. The use of vague language is considered to be effective to be informative with the least precision.

\section{CONCLUSION}

The similarities and differences are found throughout the talk among Filipino and Indonesian teachers. The total number of items found and the descriptive interpretation of the researcher is the key to show the similarities and differences. In the attitude source, teachers are expressing three of the attitude subcategories. In the category of effect, the most frequent items of Filipino teachers are found in security where speakers showed confidence, togetherness, and assurance while insecurity expressed by the Filipino teachers is considered as significant since working abroad and a long separation from family might cause insecurity. Dis/satisfaction has the least number expressed by Filipino and Indonesian in the category of effect. Filipino and Indonesian teachers use more items of positive reactions than negative ones. In the category of judgment, the Filipino teachers are more on to the positive judgment of normality and capability while the number of items from the negative judgment is found more in Indonesian's talk. Indonesian teachers concern about the norms and values of how people behave and the capability of people in accomplishing every task. Teachers expressed less judgment tenacity. The difference is there is one positive item expressed by one of the Indonesian teachers and one item found in the negative judgment expressed by Filipino teachers. In the category of engagement, the highest subcategories used by Indonesian and Filipino teachers is entertain and disclaim. There are more chances for teachers to extend the dialogic alternatives through the use of modalities such as can, could, will, etc. The most frequent modal used is"will". The items of entertain used by Filipino might express friendliness and collectiveness that involve everyone in the conversation. Indonesian teachers are more on to extend the discussion through questions as the form of closeness and kinship. Negation and denial are expressed in disclaim. In the category of proclaim, teachers show more agreement in responding to each other despite the dominant items in disclaim. In the attribute, teachers preferred to acknowledge another source to make 
such a claim. The items that expressed monoglossic feature was frequently found in Filipino teachers compared to Indonesian. The number is significant since it relates to the confidence in asserting a claim. The last appraisal resource is graduation. Both teachers are more on to the force intensification. Filipino teachers express more repetition to express feeling and to emphasize the agreement by repetition while Indonesian teachers are more on to quality intensification (very, too, etc).

\section{REFERENCES}

Andajani, S., Hadiwirawan, O., \& Sokang, Y. (2016). Current Discussion, Barriers, and Existing Stigma. Indonesian Feminist Journal.102 (4), 101111.

Caparas, M., \& Hartijasti, Y. (2017). Filipinos and Indonesians' shame: Towards integrity and soundness in organizational performance. Asian Institute of Management Working paper, 1421.

Cadwell, D., \& Rose, S. (2020). 'Going negative': An APPRAISAL analysis of the rhetoric of Donald Trump on Twitter. Language \& Communication, 70, 13-27.

Domingo R., Toledo, M., \& Mante B. (2017). Psychosocial factors influencing parental decision to allow or refuse potentially lifesaving enucleation in children with retinoblastoma. Asia Pac J Oncol Nurs 4(3), 191-196.

Efferin, S., \& Hartono, M. S. (2015). Management control and leadership styles in family business: An Indonesian case study. Journal of Accounting \& Organizational Change, 11(1), 130-159.

Fauziah, M., Warsono, \& Widhiyanto. (2019). The Comparison of Appraisal Resources in Argumentative Essays. English Education Journal, 9(4), 484 - 491.

Fraser, B. (2010). Pragmatic Competence: The Case of Hedging: Emerald Group.

Lestari, P. (2018). The Use of Attitudes as A Part of Appraisals System In The Al-Jazeera News:
Iraq war. [ Master's thesis], Universitas Negeri Semarang, Semarang, Indonesia.

Martin, J. R., \& White, P. R. R. (2005). Language of Evaluation: Appraisal in English. Palgrave Macmillan.

Morillo, H., \& Capuno, J. (2020). Views and Values on Family among Filipinos: An Empirical Exploration. Asian Journal of Social Science, 41, 5-28.

Mesa,V., \& Chang, P. (2010). The language of engagement in two highly interactive undergraduate mathematics classrooms. Linguistics and Education, 21, 83-100.

Pratiwi, A., Rukmini, D., \& Sutopo, D. (2020). The Realization of Appraisal in Eulogies Given by People of Various Relationships toward John McCain. English Education Journal, 10(1), 61 68.

Porio, E., \& Hollnsteiner, M. (1978). The Filipino Family, Community, and Nation. Ateneo de Manila Institute of Philippine Culture.

Riany, Y., Meredith., P \& Cuskelly., M. (2016). Understanding the Influence of Traditional Cultural Values on Indonesian Parenting. Routledge.

Selmer, J., \& Leon, D. (2003). Culture and management in the Philippines. In: M. Warner. Culture and Management in Asia (pp.152170). Routledge.

Thornbury, S. (2005). Beyond the sentence: introducing discourse analysis. Oxford University Press.

Hermawan, S., \& Loo, L. (2019). The Construction of Kekeluargaan as Indonesia's Organizational Culture. Jurnal Humaniora, 31(1), 1-14.

Jian, G., \& Dalisay, F. (2017). Leader-member conversational quality: Scale development and validation through three studies. Management Communication Quarterly, 28, 375-403.

Lamont, M., \& White, P. (2008) .The Evaluation of Systematic Qualitative Research in the Social Sciences. National Science Foundation.

Novi, A., Fitriati, S.W., \& Sutopo, D. (2019). The comparison between appraisal of Donald Trump and Hillary Clinton realized in the campaign speeches of the United States presidential election 2016. English Education Journal, 9(1), 25-33. 